\title{
DECOMPRESSION PATTERNS DEVELOPED BY AN INTERDEPENDENT ELECTRIC ANALOG
}

by

Gary P. Todd

Lieutenant, MC, U.S. Naval Reserve

SUBMARINE MEDICAL RESEARCH LABORATORY

U. S. NAVAL SUBMARINE MEDICAL CEN'TER REPORT No. 580

Bureau of Medicine and Surgery, Navy Department

In-House Laboratory Research Work Unit MR011.01-5009.01

Reviewed and Approved by:

Sharles 7. Scel

Charles F. Gell, M.D., D.Sc (Med)

Scientific Directos

SubMedResLab
Reviewed and Approved by:

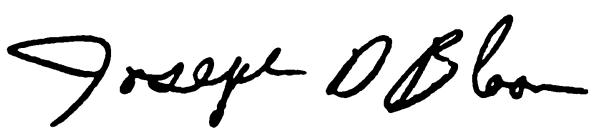

Joseph D. Bloom, CDR IC USN

Director

SubMedResLab

Approved and Released by:

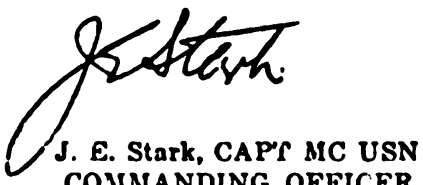

CODISINDING OFFICER

Naval Suhmarine Medical Center

This document has been approved for public release and sale; its distribution is unlimited. 